\title{
Pengembangan LKPD Gerak Harmonik Sederhana Berbasis Hands On dan Minds On Activity untuk Meningkatkan Hasil Belajar Peserta Didik
}

\author{
${ }^{1}$ Rina Ramadhani, ${ }^{2}$ Sarah Miriam, ${ }^{3}$ Saiyidah Mahtari \\ ${ }^{1,2,3}$ Prodi Pendidikan Fisika, FKIP, Universitas Lambung Mangkurat, J1. Brigjen H. Hasan \\ Basri, Kota Banjarmasin, Kalimantan Selatan 70123 \\ Email Korespondensi: rinaramadhani66@gmail.com
}

\begin{tabular}{|c|c|}
\hline Article Info & Abstract \\
\hline & \multirow{2}{*}{$\begin{array}{l}\text { Student worksheet based on hands on and minds on activity that designed to } \\
\text { improve student learning outcomes is not yet available, especially for simple } \\
\text { harmonic movement. The aims of this research are to produce simple harmonic } \\
\text { movement's student worksheet based on hands on and minds on activity that } \\
\text { are valid and practice. The model that used for this research is the ADDIE } \\
\text { model, within simple harmonic movement's student worksheet based on hands } \\
\text { on and minds on activity as the subject of this research. The subject of this } \\
\text { research is student worksheet. The data of this research is obtained from } \\
\text { validity sheets and assessment sheets of student worksheet legibility by } \\
\text { students. Data analysis was performed through the validity tests and the } \\
\text { average score of student worksheet legibility by students. This research shows } \\
\text { that: (1) the validity of simple harmonic movement's student worksheet based } \\
\text { on hands on and minds on activity is 3,23 that categorized as valid; and (2) the } \\
\text { practicality of simple harmonic movement's student worksheet based on hands } \\
\text { on and minds on activity is } 72,00 \% \text { that categorized as practice. It can be } \\
\text { concluded that simple harmonic movement's student worksheet based on hands } \\
\text { on and minds on activity can be used in the learning process. }\end{array}$} \\
\hline $\begin{array}{l}\text { Keywords } \\
\text { Hands on and minds on } \\
\text { activity; simple harmonic } \\
\text { movement; student } \\
\text { worksheet }\end{array}$ & \\
\hline Info & \\
\hline $\begin{array}{l}\text { Sejarah Artikel } \\
\text { Diterima: September } 2020 \\
\text { Direvisi: Desember } 2020 \\
\text { Dipublikasi: Desember } 2020\end{array}$ & \multirow{2}{*}{$\begin{array}{l}\text { Lembar kerja peserta didik berbasis hands on dan minds on activity yang } \\
\text { didesain untuk meningkatkan hasil belajar peserta didik masih belum tersedia, } \\
\text { terutama pada materi gerak harmonik sederhana. Tujuan penelitian yaitu } \\
\text { menghasilkan Lembar Kerja Peserta Didik gerak harmonik sederhana berbasis } \\
\text { hands on dan minds on activity yang valid dan praktis. Model yang digunakan } \\
\text { dalam penelitian ini adalah model pengembangan ADDIE dengan subjek } \\
\text { penelitian LKPD gerak harmonik sederhana berbasis hands on dan minds on } \\
\text { activity. Subjek penelitian yang digunakan adalah LKPD. Data diperoleh dari } \\
\text { lembar validitas dan lembar keterbacaan LKPD oleh peserta didik. Analisis } \\
\text { data dilakukan melalui uji validitas dan rata-rata skor keterbacaan LKPD oleh } \\
\text { peserta didik. Hasil penelitian menunjukkan bahwa: (1) validitas LKPD gerak } \\
\text { harmonik sederhana berbasis hands on dan minds on activity sebesar } 3,23 \\
\text { dengan kategori valid; dan (2) kepraktisan LKPD gerak harmonik sederhana } \\
\text { berbasis hands on dan minds on activity sebesar } 72,00 \% \text { dengan kategori } \\
\text { praktis. Diperoleh simpulan bahwa LKPD gerak harmonik sederhana berbasis } \\
\text { hands on dan minds on activity dapat digunakan pada proses pembelajaran }\end{array}$} \\
\hline $\begin{array}{l}\text { Kata kunci } \\
\text { Gerak harmo } \\
\text { hands on } \\
\text { activity; } \\
\text { LKPD }\end{array}$ & \\
\hline
\end{tabular}

Sitasi: Ramadhani, R., Miriam, S., \& Mahtari, S. (2020). Pengembangan LKPD Gerak Harmonik Sederhana Berbasis Hands On dan Minds On Activity untuk Meningkatkan Hasil Belajar Peserta Didik. Kappa Journal. $4(2), 217-224$.

\section{PENDAHULUAN}

Berdasarkan UU No. 20 Tahun 2003, pendidikan merupakan usaha sadar dan juga terencana dalam pengembangan potensi peserta didik guna mewujudkan suasana belajar aktif yang menunjang proses pembelajaran. Al Mukarram (2014) berpendapat sistem pendidikan harus dirancang dengan matang dan berkesinambungan. Pembelajaran fisika tidak bisa hanya 
diajarkan menggunakan pengajaran langsung melalui metode ceramah tanpa ada bahan ajar yang membantu pada proses pembelajaran karena peserta didik menjadi kurang mengerti dan suasana belajar terasa membosankan.

Berdasarkan hasil observasi pendahuluan yang dilakukan melalui wawancara dan angket respon peserta didik, pendidik yang ada di sana mengajarkan melalui model pengajaran langsung. Berdasarkan hasil belajar UTS fisika semester ganjil, didapatkan ratarata pencapaian hasil belajar peserta didik sebesar 51,8 yang termasuk dalam kategori penilaian yang rendah. Pendidik belum pernah menggunakan LKPD dan belum pernah menggunakan bahan dan alat praktik yang ada di laboratorium. Padahal 93,93\% peserta didik senang pelajaran fisika jika diajarkan menggunakan praktikum dan 93,93\% peserta didik senang melakukan praktikum dengan berkelompok sehingga diperlukan pembelajaran yang dapat menjadikan peserta didik aktif dan terjadi peningkatan hasil belajar oleh peserta didik. Kahar (2018) berpendapat dalam peningkatan hasil belajar dipengaruhi oleh pemilihan pengajaran yang tepat.

Sehingga diperlukan bahan ajar yang mendorong peserta didik agar aktif dalam belajar dan terjadi peningkatan hasil belajar oleh peserta didik. Salah satu bahan ajar yang mendorong peserta didik agar aktif dalam belajar ialah LKPD. LKPD merupakan lembar tugas yang dikerjakan peserta didik pada proses pembelajaran, LKPD berisi petunjuk untuk menyelesaikan tugas yang sesuai dengan KD dan indikator yang harus dicapai (Putri, 2017). Menurut penelitian yang dilakukan oleh Ardhiantari (2015), LKPD yang sudah ada kadangkadang kurang memperhatikan terhadap persyaratan pembuatan LKPD dan tidak membangun pengetahuan peserta didik. LKPD yang sudah ada juga membuat peserta didik kesulitan untuk memahami bahasa yang digunakan, tidak adanya penyajian gambar, desain yang kurang menarik peserta didik untuk membaca, dan soal-soal yang ada pada LKPD terlalu sulit sehingga membuat peserta didik pasif.

Penggunaan LKPD yang dapat menjadikan peserta didik aktif dan terjadi peningkatan hasil belajar oleh peserta didik salah satunya dengan pendekatan Hands on dan Minds on Activity. Menurut Asmawati (2017), Hands on Activity adalah pendekatan yang membuat peserta didik terlibat total dalam menemukan materi sehingga dapat mengaitkannya dengan kehidupan sehari-hari. Minds on Activity menurut Aini (2014) adalah aktivitas psikis yang dilakukan agar peserta didik dapat mengumpulkan dan mengolah informasi yang didapat saat melakukan kegiatan di laboratorium sehingga peserta didik menemukan suatu konsep baru yang teratur pada struktur kognitif sehingga penggunaan LKPD dengan pendekatan Hands on dan Minds on Activity dapat mendorong peserta didik agar aktif dalam belajar. Hal ini sesuai dengan karakteristik materi Gerak Harmonik Sederhana yang memuat dua buah percobaan, yaitu getaran pegas dan ayunan bandul sederhana yang dapat menggunakan pendekatan Hands on Activity atau aktivitas fisik dan pada materi Gerak Harmonik Sederhana juga memuat analisis matematik untuk mendapatkan persamaan yang juga dapat menggunakan pendekatan Minds on Activity atau aktivitas berpikir sehingga Hands on dan Minds on Activity cocok dengan materi tersebut. Hal ini dibuktikan melalui penelitian yang dilakukan Aini (2014) bahwa penggunaan Hands on dan Minds on Activity terjadi peningkatan pada hasil belajar peserta didik dan penelitian yang dilakukan oleh Kurniawan (2017) bahwa Hands on dan Minds on Activity memiliki pengaruh pada hasil belajar peserta didik.

Berdasarkan pemaparan tersebut, peneliti mengembangkan LKPD Gerak Harmonik Sederhana berbasis Hands on dan Minds on Activity untuk meningkatkan hasil belajar peserta didik. Berdasarkan latar belakang tersebut, rumusan masalah yang diambil secara umum "Bagaimana kelayakan LKPD Gerak Harmonik Sederhana berbasis Hands on dan Minds on Activity untuk meningkatkan hasil belajar peserta didik?". 


\section{METODE}

Penelitian ini adalah penelitian pengembangan. Penelitian pengembangan digunakan untuk mengembangkan LKPD Gerak Harmonik Sederhana berbasis Hands on dan Minds on Activity untuk meningkatkan hasil belajar peserta didik. Penelitian ini menggunakan langkahlangkah model pengembangan ADDIE, yaitu Analysis (analisis), Design (perancangan), Development (pengembangan), Implementation (uji coba), dan Evaluation (evaluasi) (Rahmatin, 2019).

Subjek pada penelitian ini adalah LKPD Gerak Harmonik Sederhana. Data diperoleh melalui keterbacaan LKPD dengan peserta didik kelas X MIPA 2 SMA Negeri 11 Banjarmasin sebagai responden. Instrumen yang digunakan berupa lembar validasi LKPD untuk mengukur validitas LKPD dan lembar keterbacaan LKPD oleh peserta didik untuk mengukur kepraktisan dari LKPD yang dikembangkan. Data diperoleh dari hasil Validitas yang didapatkan dari rata-rata skor nilai pada tiap aspek yang diberikan validator, lalu disesuaikan dengan kategori yang telah ditentukan (Widoyoko, 2016). Reliabilitas LKPD menggunakan persamaan Alpha Cronbach.

Penilaian praktis atau tidaknya LKPD yang dikembangkan dapat diukur berdasarkan penilaian dari lembar keterbacaan LKPD yang diisi secara online melalui google form. Teknik analisis data untuk kepraktisan LKPD secara deskriptif kuantitatif dengan menghitung persentase kepraktisan dengan pengkategorian Akbar (2016) pada Tabel 1.

Tabel 1. Kriteria Kepraktisan LKPD

\begin{tabular}{ccc}
\hline No. & Rata-Rata & Kategori \\
\hline 1. & $81 \%-100 \%$ & Sangat Praktis \\
2. & $61 \%-80 \%$ & Praktis \\
3. & $41 \%-60 \%$ & Cukup Praktis \\
4. & $21 \%-40 \%$ & Kurang Praktis \\
5. & $0 \%-20 \%$ & Sangat Kurang Praktis \\
\hline
\end{tabular}

\section{HASIL DAN PEMBAHASAN}

Produk yang dikembangkan pada penelitian ini adalah LKPD Gerak Harmonik Sederhana berbasis Hands on dan Minds on Activity yang dikembangkan untuk meningkatkan hasil belajar peserta didik.
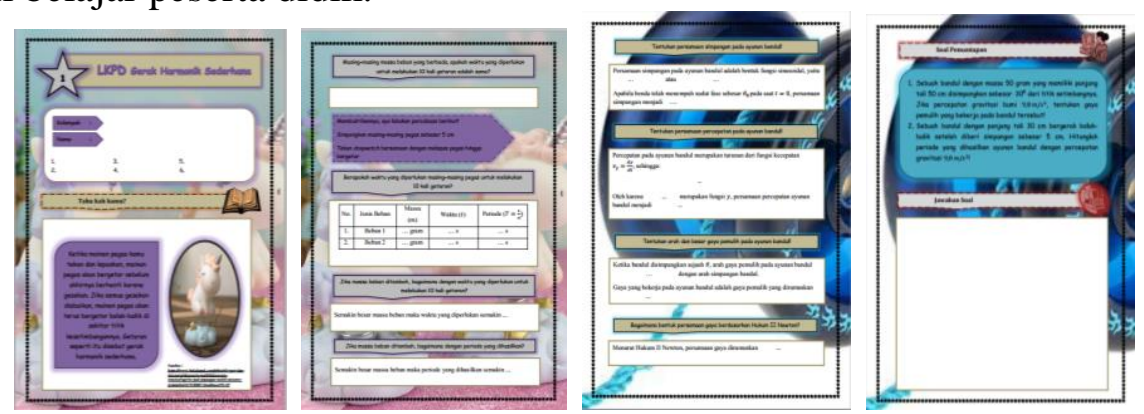

Gambar 1. LKPD Gerak Harmonik Sederhana

\section{Hasil Validitas}

Hasil validitas bertujuan memperoleh pendapat dari para ahli terhadap substansi LKPD Gerak Harmonik Sederhana berbasis Hands on dan Minds on Activity yang dilakukan oleh 5 orang validator ahli, yaitu dosen ahli serta pendidik Fisika 
Tabel 2. Hasil Validitas LKPD

\begin{tabular}{cccc}
\hline No. & Aspek Penilaian & Rata-Rata & Kategori \\
\hline 1. & Didaktik & 3,28 & Valid \\
2. & Konstruksi & 3,20 & Valid \\
3. & Teknik & 3,37 & Valid \\
4. & Hands on Activity & 3,17 & Valid \\
5. & Minds on Activity & 3,14 & Valid \\
\hline Validitas & & 3,23 & Valid \\
Reliabilitas & & 0,77 & Tinggi \\
\hline
\end{tabular}

Data pada Tabel 2 menunjukkan aspek penilaian pada LKPD Gerak Harmonik Sederhana berbasis Hands on dan Minds on Activity berkategori valid dengan reliabilitas tinggi. LKPD Gerak Harmonik Sederhana berbasis Hands on dan Minds on Activity direvisi sesuai dengan saran dan masukan lima orang validator, meliputi penambahan cover LKPD, daftar isi, pendahuluan mengenai penjelasan Hands on dan Minds on Activity, serta penambahan pertanyaan aktivitas pada LKPD mengenai analisis matematik untuk mendapatkan persamaan.

a. Aspek Didaktik

LKPD dibuat dengan jenis LKPD semi terbuka yang memberi peserta didik kesempatan untuk mengembangkan kreativitas dengan beberapa batasan. Beberapa bagian konten LKPD dipersiapkan pendidik terlebih dahulu sehingga bagian yang harus dikembangkan oleh peserta didik dikembangkannya secara mandiri (Suhartini, 2019).

LKPD dibuat dengan pertanyaan-pertanyaan untuk menggiring peserta didik menemukan konsep. LKPD dibuat dengan melakukan percobaan sesuai dengan petunjuk sehingga peserta didik membuat pengalaman belajar mereka sendiri karena langsung mempraktikkan apa yang dipelajari.

Hal ini didukung dengan penelitian Putra (2018) pada aspek didaktik, cara penyajian materi LKPD sesuai dengan pembelajaran sehingga peserta didik dapat membangun pengetahuannya dalam pemahaman konsep dan juga meningkatkan penalaran matematis.

b. Aspek Konstruksi

LKPD yang berkualitas menurut Suhartini (2019) harus tersusun dengan logis dan sistematis sehingga memiliki kontekstualitas yang tinggi dan memerlukan penyeleksian konsep yang harus dipahami peserta didik. Bahasa dan kalimat LKPD harus mudah untuk dipahami peserta didik kelas X. LKPD dibuat dengan petunjuk-pentujuk agar mengarahkan peserta didik kepada jawaban yang tepat. Sumber LKPD harus mengacu pada buku yang dimiliki peserta didik sehingga dapat memudahkan peserta didik. LKPD yang dibuat harus memberikan kolom yang cukup sehingga peserta didik leluasa untuk menulis dan menggambar. LKPD diberikan bingkai sehingga peserta didik menulis dan menggambar pada kolom jawaban yang juga memudahkan pendidik untuk memeriksa jawaban peserta didik.

Pratiwi (2015) berpendapat bahwa peserta didik akan mudah memahami LKPD jika kalimat yang digunakan sederhana dan tidak bertele-tele sehingga LKPD dibuat dengan kalimat singkat tetapi mudah dipahami.

Hal ini didukung dengan hasil penelitian Ardhantari (2015) pada aspek konstruksi, yaitu responden menyatakan sangat setuju dan setuju dari pernyataan yang mendukung. Tidak ada jawaban yang menyatakan kurang setuju. Aspek konstruksi pada LKPD seluruhnya dapat dikatakan sudah sesuai untuk pembelajaran disekolah.

c. Aspek Teknik

Pratiwi (2015) mengemukakan pendapat bahwa penampilan LKPD perlu diperhatikan karena peserta didik akan tertarik melalui penampilan LKPD bukan pada isinya. 
LKPD dikembangkan menggunakan huruf cetak dan tebal dengan ukuran besar sehingga mudah dibaca oleh peserta didik dan menggunakan bingkai untuk membedakan kolom pertanyaan dengan kolom jawaban, juga kalimat yang digunakan singkat agar mudah dipahami. LKPD dibuat dengan gambar yang ukurannya disesuaikan dengan besar tulisan.

Hal ini didukung dengan penelitian Aulia (2016) pada aspek teknik, perangkat pembelajaran yang telah dikembangkan dinyatakan valid yang artinya dari segi desain dan penyajian telah dikemas dengan baik dan dapat diaplikasikan dalam proses pembelajaran. Pemilihan jenis huruf dan warna memudahkan peserta didik dalam membaca serta menarik perhatian peserta didik.

\section{d. Aspek Hands on Activity}

Kegiatan LKPD dirancang agar mengajarkan peserta didik untuk menciptakan suatu peralatan yang menggunakan prinsip gerak harmonik sederhana sehingga memberikan pengalaman baru bagi peserta didik. Kegiatan LKPD dirancang untuk membuat peserta didik menggunakan indera yang berbeda di kelas sains sehingga memberikan pengalaman langsung pada peserta didik dalam kehidupan sehari-hari. LKPD dikembangkan dengan keterbaruan, yaitu memuat pertanyaan-pertanyaan yang hanya bisa dijawab jika peserta didik melakukan aktivitas fisik (Hands on Activity) agar peserta didik aktif menggunakan indera yang berbeda di kelas sains untuk menggali informasi yang dapat menciptakan suatu peralatan yang menggunakan prinsip fisika sehingga peserta didik mendapat pengalaman baru yang langsung bisa diterapkan. Hal ini sesuai dengan pendapat Asmawati (2017) bahwa Hands on Activity adalah pendekatan yang membuat peserta didik terlibat total dalam penemuan materi sehingga terdorong untuk mengaitkannya pada kehidupan sehari-hari. Hal ini didukung dengan penelitian Yuliati (2011) bahwa pembelajaran fisika berbasis Hands on Activity menjadikan peserta didik aktif terlibat langsung pada proses pembelajaran. Peserta didik dilatih menerapkan pengetahuannya dalam pembuatan suatu alat kapal selam sederhana.

e. Aspek Minds on Activity

LKPD dirancang dengan penyusunan kegiatan yang menjadikan peserta didik aktif mengumpulkan dan mengolah informasi sehingga peserta didik menemukan suatu konsep baru yang teratur pada struktur kognitif. LKPD dikembangkan dengan keterbaruan, yaitu LKPD dibuat dengan pertanyaan yang hanya bisa dijawab dengan aktivitas berpikir (Minds on Activity) setelah mendapatkan konsep dari pertanyaan aktivitas fisik (Hands on Activity) sehingga peserta didik mengumpulkan dan memproses informasi untuk menemukan suatu konsep baru yang tertata dengan aktivitas yang memberikan penghayatan secara mendalam terhadap pembelajaran dan peserta didik termotivasi untuk membangun proses berpikir sehingga terjadi peningkatan hasil belajar peserta didik. Sesuai dengan pendapat Aini (2014), yaitu dengan adanya kegiatan Minds on Activity peserta didik akan termotivasi dan menjadikan pembelajaran menyenangkan dan bermakna, serta terjadi peningkatan hasil belajar peserta didik.

Hal ini didukung dengan penelitian Kurniawan (2017), Minds on Activity berpengaruh pada hasil belajar peserta didik. Aktivitas berpikir (Minds on Activity) terjadi saat penemuaan konsep pada percobaan, menguji hipotesis, membuat kesimpulan serta mengkomunikasikannya dengan diskusi.

\section{Hasil Kepraktisan}

Kepraktisan LKPD Gerak Harmonik Sederhana berbasis Hands on dan Minds on Activity ini diukur berdasarkan lembar keterbacaan LKPD oleh 34 peserta didik. 
Tabel 3. Hasil Kepraktisan LKPD

\begin{tabular}{cccc}
\hline No. & Aspek Penilaian & Rata-Rata & Kategori \\
\hline 1. & Kemenarikan & $70,22 \%$ & Praktis \\
2. & Isi & $73,35 \%$ & Praktis \\
3. & Kemudahan & $71,69 \%$ & Praktis \\
\hline Kepraktisan & & $72,00 \%$ & Praktis \\
Reliabilitas & & 0,89 & Sangat Tinggi
\end{tabular}

Data pada Tabel 3 menunjukkan kepraktisan LKPD Gerak Harmonik Sederhana berbasis Hands on dan Minds on Activity yang dilihat dari lembar keterbacaan LKPD oleh peserta didik. Keterbacaan LKPD dilakukan untuk memperoleh informasi apakah LKPD yang dikembangkan mudah dipahami dan terbaca secara jelas oleh peserta didik. Dari 34 orang peserta didik, $79,4 \%$ peserta didik menyatakan bahwa tampilan gambar dan warna pada cover LKPD membuat mereka tertarik untuk membacanya, serta jenis dan juga ukuran huruf pada LKPD cocok dan nyaman untuk dibaca.

Sebanyak 82,3\% peserta didik menyatakan tata letak LKPD bagus dan ideal sehingga peserta didik dengan mudah dapat membaca runtutan kegiatan pada LKPD. Dengan membaca LKPD secara sekilas, 79,4\% peserta didik langsung dapat membedakan bagianbagian LKPD, seperti Pendahuluan, Langkah Kerja, Pertanyaan Aktivitas, dan Soal Pemantapan. Sebanyak $82,4 \%$ peserta didik menyatakan bahwa susunan kegiatan pada LKPD membuat mereka aktif dalam pembelajaran

Pertanyaan - pertanyaan aktivitas pada LKPD mudah dimengerti sehingga 73,5\% peserta didik dapat melakukannya dengan mudah dan 70,6\% peserta didik berpendapat bahwa pertanyaan-pertanyaan pada Soal Pemantapan juga mudah dipahami. Pertanyaanpertanyaan aktivitas menurut Asmawati (2017) adalah pendekatan yang membuat peserta didik terlibat secara penuh sehingga $88,2 \%$ peserta didik merasa kegiatan pada LKPD menuntut mereka melakukan aktivitas berpikir untuk menemukan jawaban.

Bahasa yang digunakan dalam LKPD secara umum telah sesuai sehingga $88,2 \%$ peserta didik mudah memahaminya, serta kalimat yang dipakai pada LKPD bukan bermakna banyak sehingga $73,5 \%$ peserta didik juga mudah memahaminya. Hal ini telah sesuai dengan pendapat Pratiwi (2015), yaitu penggunaan bahasa yang disesuaikan tingkat pemahaman peserta didik serta struktur kalimat yang digunakan jelas.

Pada LKPD terdapat ruang jawab yang cukup sehingga $82,4 \%$ peserta didik bisa leluasa untuk menulis dan menggambar. Sehingga setelah membaca LKPD, 67,6\% peserta didik berminat untuk mengikuti pembelajaran Gerak Harmonik Sederhana dengan aktivitasaktivitas pembelajaran.

Hal ini didukung melalui hasil penelitian Ardhantari (2015) pada hasil respon peserta didik terhadap keterbacaan LKPD, LKPD dapat terbaca dan tidak bermakna banyak terhadap penulisan dan juga kalimat pada LKPD sehingga peserta didik mudah dalam mempelajari LKPD walaupun tanpa bimbingan pendidik

\section{KESIMPULAN}

Berdasarkan pada hasil pengembangan serta hasil penelitian sehingga diperoleh simpulan, yaitu (1) Validitas LKPD Gerak Harmonik Sederhana Berbasis Hands on dan Minds on Activity yang dilihat dari penilaian validator berkategori valid dan (2) Kepraktisan LKPD Gerak Harmonik Sederhana Berbasis Hands on dan Minds on Activity yang dilihat dari lembar keterbacaan LKPD oleh peserta didik berkategori praktis.

\section{SARAN}

Berdasarkan hasil penelitian maka peneliti menyampaikan beberapa saran, yaitu (1) Bagi pendidik, penggunaan pendekatan Hands on dan Minds on Activity harus disampaikan 
dengan sungguh-sungguh agar sasaran yang dituju tepat dan dilakukan dengan kegiatan yang membuat peserta didik dekat dengan kondisi sebenarnya dan (2) Bagi mahasiswa, penelitian ini dapat digunakan sebagai bahan rujukan untuk membantu berkembangnya penelitian sejenis ini dengan perbaikan-perbaikan atas kelemahan penelitian yang tercantum.

\section{UCAPAN TERIMA KASIH}

Ucapan terima kasih terutama ditujukan kepada program studi pendidikan fisika FKIP yang telah memberi kesempatan dalam penelitian ini.

\section{DAFTAR PUSTAKA}

Aini, K. (2014). Penerapan Model Pembelajaran Inkuiri dengan Hands on Minds on Activity untuk Meningkatkan Hasil Belajar Siswa pada Materi Pokok Termokimia (Implementation Inquiry Learning Model with Hands on Minds on Activity to Improve Student's Achievments At Thermochemistry). UNESA Journal of Chemical Education,3(1).

Al Mukarram, A., Hartini, S., \& Wati, M. (2014). Pengembangan Lembar Kegiatan Siswa (LKS) dan Media Pembelajaran IPA SMP Berbasis Keterampilan Berpikir Kritis. Berkala Ilmiah Pendidikan Fisika, 2(3), 253-264.

Aulia, A. (2016). Validitas Perangkat Pembelajaran Biologi Berorientasi Model Problem Based Learning (PBL) Bermuatan Karakter. BioCONCETTA, 2(1), 128-141.

Ardhiantari, W., Fadiawati, N., \& Kadaritna, N. (2015). Pengembangan LKS berbasis keterampilan proses sains pada materi hukum-hukum dasar kimia. Jurnal Pendidikan dan Pembelajaran Kimia, 4(1), 312-323.

Asmawati, A., Karmana, I. W., \& Hunaepi, H. (2017). Pengaruh Pendekatan Kontekstual Berbasis Hands on Activity terhadap Keterampilan Proses Sains dan Kemampuan Kognitif Siswa. Prisma Sains: Jurnal Pengkajian Ilmu dan Pembelajaran Matematika dan IPA IKIP Mataram, 5(2), 33-41.

Kahar, M. S. (2018). Pengembangan perangkat pembelajaran fisika dengan menggunakan model pembelajaran kooperatif tipe STAD. JIPF (Jurnal Ilmu Pendidikan Fisika), 2(2), 42-49.

Kurniawan, W., Ertikanto, C., \& Suana, W. (2017). Pengaruh Hands on Minds on Activity Terhadap Hasil Belajar Melalui Inkuiri Terbimbing. Jurnal Pembelajaran Fisika, 5(2).

Pratiwi, Rizka. 2015. Pengembangan Lembar Kegiatan Peserta Didik Materi Energi Panas dan Bunyi Berbasis Model Project Based Learning dengan Teknik Mind Mapping untuk Kelas IV Sekolah Dasar.Skripsi Sarjana. Universitas Muhammadiyah Purwokerto, Purwokerto. Tidak dipublikasikan.

Putra, A., Syarifuddin, H., \& Zulfah, Z. (2018). Validitas Lembar Kerja Peserta Didik Berbasis Penemuan Terbimbing dalam Upaya Meningkatkan Pemahaman Konsep dan Kemampuan Penalaran Matematis. Edumatika: Jurnal Riset Pendidikan Matematika, 1(2), 56-62.

Putri, Agnesi S. 2017. Pengembangan Lembar Kerja Peserta Didik (LKPD) Berbasis Learning Cycle 7e Tema "Bahaya Rokok bagi Pernapasan" untuk Meningkatkan 
Scientific Literacy Peserta Didik. Thesis Magister. Universitas Negeri Yogyakarta, Yogyakarta. Tidak dipublikasikan.

Rahmatin, Lia S. 2019. Pengembangan Lembar Kegiatan Peserta Didik (LKPD) Berbasis Learning Cycle 5e untuk Meningkatkan Keterampilan Proses Sains dan Sikap Ilmiah Peserta Didik Kelas X pada Materi Tumbuhan di SMA Negeri 1 Pakem. Thesis Magister. Universitas Negeri Yogyakarta, Yogyakarta. Tidak dipublikasikan.

Suhartini. 2019. Pengembangan LKPD Berbasis PBL pada Pokok Bahasan Sistem Respirasi untuk Melatih Literasi Kuantitatif dan Sikap Ilmiah Peserta Didik SMA Kelas XI IPA. Skripsi Sarjana. Universitas Negeri Yoygyakarta, Yogyakarta. Tidak dipublikasikan.

UU No. 20 Tahun 2003 tentang Sistem Pendidikan Nasional.

Yuliati, D. I., Yulianti, D., \& Khanafiyah, S. (2011). Pembelajaran fisika berbasis hands on activities untuk menumbuhkan kemampuan berpikir kritis dan meningkatkan hasil belajar siswa SMP. Jurnal Pendidikan Fisika Indonesia, 7(1). 